\title{
Predictors of Acute Kidney Injury and Mortality in Intensive Care Unit at a Teaching Tertiary Hospital_ID
}

\author{
Justor Banda ${ }^{1}$, Natasha Chenga ${ }^{2}$, Suwilanji Nambaya ${ }^{3}$, Tela Bulaya ${ }^{4}$, Seter Siziya ${ }^{5}$
}

\begin{abstract}
Background and aims: Despite the increased rates of acute kidney injury (AKI) in intensive care units (ICU) and associated mortality, information on the epidemiology of AKI is sparse in sub-Saharan Africa (SSA). We investigated the rates and predictors of AKI and associated mortality in a tertiary ICU.

Materials and methods: This retrospective study analyzed 280 hospital records of patients admitted to the ICU at a tertiary teaching hospital who were aged $\geq 15$ years from January 2017 to May 31, 2018. The outcome parameters of the study were rates of AKI in the ICU, associated risk factors, and mortalities. Acute kidney injury and ICU mortality were established by the multivariate logistic analysis.

Results: The median age was 36 years (IQR 28, 52). The rate of AKI was 52.9\%, and the presence of human immunodeficiency virus (HIV) and oliguria was 2.3-fold (0.004) and 4-fold (0.016) positive predictors of ICU-AKI, respectively. Male gender (0.003), diabetes mellitus (DM) (0.010), respiratory disease (0.001), inotropes (0.004), and ventilator support (0.017) were predictors for ICU mortality after controlling for confounders. Conclusion: The rate of AKI is significantly higher in a referral tertiary hospital in Zambia compared to developed countries and the presence of HIV and noncommunicable diseases such as DM impacts severely on outcomes.

Keywords: Acute kidney injury, Intensive care unit, Mortality, Predictors.

Indian Journal of Critical Care Medicine (2020): 10.5005/jp-journals-10071-23352
\end{abstract}

\section{INTRODUCTION}

Yearly, acute kidney injury (AKI), a sudden deterioration in kidney function, affects more than 13 million people globally leading to almost 2 million deaths. ${ }^{1-3}$ Almost $80 \%$ of the AKI burden occurs in low- and middle-income countries (LMIC). ${ }^{1,3}$

The incidence of $\mathrm{AKI}$ varies according to geographical location, etiological factors, and health resources; however, $\mathrm{AKI}$ is significantly higher in LMIC such as sub-Saharan Africa (SSA) ${ }^{1}$ and is linked with longer hospital stay, higher hospital, and mortality. 2,4,5 In hospitalized patients, the incidence of AKI is $20 \%$ and is as high as $60 \%$ in patients admitted to intensive care units (ICUs). ${ }^{6}$ Despite recent global "zero by 25 " initiatives call to end AKI-related mortality by $2025,{ }^{1}$ in a recent multicenter prospective study of hospitalized patients admitted to ICU in Egypt, ElHafeez et al. reported $40 \%$ incidence of AKI within 24 hours of admission to the ICU.'

Development of AKI in ICU is associated with increased morbidity and mortality. In a study of 279 hospitalized patients to the ICU, mortality was $71.7 \%$ vs $14.4 \%(p<0.001)$ in the AKI vs the non-AKI group. ${ }^{2}$ In this study, AKI development was a 10 -fold independent predictor of mortality. ${ }^{2}$ Late presentations to hospitals and nonaccessibility of dialysis facilities contribute to the increased mortality in SSA. ${ }^{7}$ In systemic review of 41 studies with 1,401 adults and 1,937 children, $70 \%$ of the adults required dialysis; however, only $33 \%$ accessed it. ${ }^{7}$

Sub-Saharan Africa has sparse data on incidence of AKI in ICU and associated outcomes, and AKI impacts severely on morbidity and mortality due to suboptimal diagnosis, late presentation to hospitals, and fewer hospitals offering renal replacement therapy. ${ }^{3,7}$

Knowing the pattern and outcomes of AKI is important in guiding hospital and government policy. This study, therefore, investigated the rates and outcomes of AKI in ICU at a referral tertiary hospital.

\footnotetext{
1,3 Department of Internal Medicine, Division of Nephrology, Ndola Teaching Hospital, Ministry of Health, Zambia

${ }^{2,4}$ Department of Internal Medicine, Ndola Teaching Hospital, Ministry of Health, Zambia

${ }^{5}$ Department of Internal Medicine, Division of Nephrology, Michael Chilufya Sata Medical School, Copper Belt University, Ndola, Zambia

Corresponding Author: Justor Banda, Department of Internal Medicine, Division of Nephrology, Ndola Teaching Hospital, Ministry of Health, Zambia, Phone: +260 969648 300, e-mail: katusib@yahoo. co.uk
}

How to cite this article: Banda J, Chenga N, Nambaya S, Bulaya T, Siziya S. Predictors of Acute Kidney Injury and Mortality in Intensive Care Unit at a Teaching Tertiary Hospital_ID. Indian J Crit Care Med 2020;24(2):116-121.

Source of support: Nil

Conflict of interest: None

\section{Materials and Methods}

\section{Study Design, Setting, and Population}

A retrospective analysis of 280 hospital records of patients admitted to the ICU from January 2017 to May 2018 (16 months) at a tertiary teaching hospital, in Zambia, was performed after acquiring ethics approval. All ICU patients' records admitted during the 16 months' period were considered for eligibility. Inclusion criteria were patients aged $\geq 15$ years without evidence of chronic kidney disease (CKD) or end-stage kidney disease (ESKD) and were not on chronic renal replacement therapy based on file records. About 120 patients' files with missing information were excluded from the study.

() The Author(s). 2020 Open Access This article is distributed under the terms of the Creative Commons Attribution 4.0 International License (https://creativecommons. org/licenses/by-nc/4.0/), which permits unrestricted use, distribution, and non-commercial reproduction in any medium, provided you give appropriate credit to the original author(s) and the source, provide a link to the Creative Commons license, and indicate if changes were made. The Creative Commons Public Domain Dedication waiver (http://creativecommons.org/publicdomain/zero/1.0/) applies to the data made available in this article, unless otherwise stated. 


\section{Study Procedures}

Hospital record data were reviewed for age; gender; presence of comorbidities such as diabetes mellitus (DM), HIV, hypertension, cardiovascular, respiratory, and neurological diseases; and also for admission diagnosis and outcome variables (discharge from ICU or mortality). Laboratory records were reviewed to determine the hematological and biochemical status of patients for presence of anemia or renal disease, respectively. Patient records were subsequently clustered into AKI and non-AKI groupings.

\section{Study Definitions and Outcomes of the Study}

The primary outcomes were presence of AKI, ICU mortality, and associated risk factors. The diagnosis of AKI was based on the AKIKidney Disease Improving Global Outcomes (AKI-KDIGO) criteria (rising serum creatinine and reducing urine output $<0.5 \mathrm{~mL} / \mathrm{kg}$ per hour for 6-12 hours. $^{6}$

Patients without a record of CKD and/or with estimated glomerular filtration rate above $60 \mathrm{~mL} /$ minute/1.73 $\mathrm{m}^{2}$ and/or normal imaging findings were considered to have AKI when AKIKDIGO criteria were met. Sepsis and septic shock were defined according to the survival sepsis guidelines. ${ }^{8,9}$

\section{Statistical Analysis}

Raw data were stored in MS Excel and analyzed using Stata version 13. Nonparametric variables were reported as medians with interquartile ranges while categorical variables were presented as proportions. Comparisons of proportions were established using Mann-Whitney or Pearson's Chi-squared tests when appropriate at the $5 \%$ significance level. Correlates for AKI and ICU mortality were established using the logistic regression analysis.

All factors significant at the $10 \%$ level in bivariate analyses were considered in the multivariate logistic regression analysis. The stepwise backward likelihood ratio variable selection method was used with an enter probability of 0.05 and a removal probability of 0.05 . Unadjusted odds ratios (OR) and adjusted odds ratios (AOR) together with their $95 \%$ confidence intervals were reported.

\section{Results}

\section{Characteristics of Participants}

Altogether 280 patients' records were reviewed and their results are reported in Table 1. A total of 143 (51\%) ICU patients were from internal medicine, 89 (32\%) from surgery, and 48 (17\%) from obstetrics and gynecology departments, respectively. The median age was $36(28,52)$ of which $51.1 \%$ were male. Overall, $72.3 \%$ of the patients were below the age of 50 years, $13.8 \%$ were diabetic, $27 \%$ hypertensive, and $49.4 \%$ had oliguria. Almost $40 \%$ of patients were HIV-infected and a higher proportion were males (49.3\%) than females $(30.3 \%, p=0.016)$. The rate of AKI was $52.9 \%$ and ICU mortality was higher in the AKI compared to the non-AKI group (74.1\% vs $61.4 \%, p=0.022$ ). While no significant difference was observed in rates of AKI between gender $(p=0.173)$, mortality was significantly higher in males $(p=0.013)$.

\section{Determinants of AKI}

Table 2 shows factors associated with AKI in bivariate and multivariate analyses. Patients with HIV, cardiac disease, and oliguria were more likely to have AKI compared to those without. HIV-positive patients were about twice $[A O R=2.38,95 \% \mathrm{Cl}(1.33$, 4.26)] more likely to have AKI compared to HIV-negative patients.
Patients with oliguria were $4.23[95 \% \mathrm{Cl}(2.43,7.34)]$ times more likely to have AKI compared to patients without oliguria.

\section{Determinants of ICU mortality}

Factors associated with ICU mortality in bivariate and multivariate analyses are shown in Table 3. Male gender, diabetes mellitus, respiratory disease, inotrope, and ventilation support were independently associated with ICU mortality. Compared to female patients, male patients were $75 \%[\mathrm{AOR}=1.73,95 \% \mathrm{Cl}(1.21,2.47)]$ more likely to die in ICU.

Patients with DM were 2.82 [95\% Cl $(1.28,6.24)]$ times more likely to die in ICU compared to those without it. Compared to patients without respiratory disease, those with respiratory disease were $2.57[95 \% \mathrm{Cl}(1.43,4.59)]$ times more likely to die in ICU. Patients on inotrope support were $77 \%[A O R=1.77,95 \% \mathrm{Cl}(1.20,2.62)]$ more likely to die compared to those not on the support. Compared to patients not on the ventilation support, those on the ventilation support were $57 \%[A O R=1.57,95 \% \mathrm{Cl}(1.08,2.27)]$ more likely to die.

\section{Discussion}

Our study findings demonstrated the significant high rate of AKI in the ICU in a low-income country and the association between HIV infection and noncommunicable diseases such DM with AKI and mortality among patients admitted to our ICU.

The rate of AKI in our study was $52.9 \%$, which is higher than what is reported in developed countries. ${ }^{1,10}$ However, the reported incidence of AKI in this present study is consistent with findings in LMIC in which the rate may be as high as $60 \%$., ${ }^{7,11}, 12$ The rate of AKI is influenced by several factors that include geographical location, infection rate, and social and economic determinants. ${ }^{1,2,13}$

In an observational prospective study of trauma patients in Brazil, Santos et al. found a $33.3 \%$ incidence of AKI in ICU while a $40 \%$ incidence was found in a multicenter study of ICU in teaching hospitals specializing in surgery and medicine in Egypt. ${ }^{1,2}$ Furthermore, Tejera et al. in Uruguay reported a 50\% incidence of AKI among patients hospitalized to ICUs. ${ }^{5}$

Interesting to this study was the twofold positive and highlighted association of HIV with AKI development in the ICU. Acute kidney injury is a common presentation in HIV-infected patients and presence of HIV infection is associated with a fourfold risk of renal disease compared to uninfected HIV patients. ${ }^{14-19}$ Vachiat et al. in a retrospective analysis of 684 patients hospitalized with renal failure in Johannesburg, South Africa, reported a $60 \%$ incidence of AKI in the HIV-infected group. ${ }^{15}$ In this study, the sepsis rate was significantly high in the HIV-infected vs the uninfected HIV patients. ${ }^{15} \mathrm{Li}$ et al. reported a $15 \%$ incidence of AKI among HIV-infected patients in the United States. ${ }^{19}$ In this study, presence of low CD4 count, black ethnicity, and high viral load contributed to AKI development.

Multifactorial HIV- and non-HIV-related factors influence development of AKI in HIV-infected patients. ${ }^{20-24}$ The decreased immunity, nephrotoxic medications for HIV and opportunistic infections, and underlying subclinical renal disease occurring in HIV-infected patients are all significant determinants for AKI development. ${ }^{22,23,25}$ In a cohort study of 489 HIV-infected patients, the presence of acquired human deficiency virus (AIDS), nephrotoxic medications, and sepsis were, respectively, associated with a 2.7-fold, 2.8-fold, and 23-fold odds for developing AKI. ${ }^{20}$ Furthermore, Wyatt et al. in a U.S. study of pre-highly active antiretroviral therapy (HAART) and post-HAART patients reported 
Table 1: Descriptive table of indexed patients

\begin{tabular}{|c|c|c|c|c|c|}
\hline \multirow[b]{2}{*}{ Characteristic } & & \multirow{2}{*}{$\begin{array}{l}\text { Total (280) } \\
n(\%)\end{array}$} & \multirow{2}{*}{$\begin{array}{l}\text { Male (142) } \\
p \text { value }\end{array}$} & \multicolumn{2}{|c|}{ Female (138) } \\
\hline & & & & $n(\%)$ & $p$ value \\
\hline \multirow[t]{2}{*}{ Age (years) } & $<50$ & $204(72.3)$ & $100(70.9)$ & $102(75)$ & 0.445 \\
\hline & $>50$ & $76(27.1)$ & $42(30)$ & $36(27)$ & \\
\hline \multirow[t]{2}{*}{ Diabetes mellitus } & Yes & $36(13.8)$ & 19 (14.2) & $17(13.4)$ & 0.853 \\
\hline & No & $225(86.2)$ & $115(85.8)$ & $110(86.6)$ & \\
\hline \multirow[t]{2}{*}{ Hypertension } & Yes & $71(27.0)$ & $35(25.9)$ & $36(28.1)$ & 0.688 \\
\hline & No & $192(73.0)$ & $100(74.1)$ & $92(71.9)$ & \\
\hline \multirow[t]{2}{*}{ HIV positive } & Yes & $60(38.5)$ & $33(49.3)$ & $27(30.3)$ & 0.016 \\
\hline & No & $96(61.5)$ & $34(50.7)$ & $62(69.7)$ & \\
\hline \multirow[t]{2}{*}{ Sepsis } & Yes & $132(49.3)$ & $66(48.5)$ & $66(50.0)$ & 0.810 \\
\hline & No & $136(50.7)$ & $70(51.5)$ & $66(50.0)$ & \\
\hline \multirow[t]{2}{*}{ Cardiac disease } & Yes & $46(17.2)$ & $22(16.3)$ & $24(18.0)$ & 0.704 \\
\hline & No & $222(82.8)$ & $113(83.7)$ & $109(82.0)$ & \\
\hline \multirow[t]{2}{*}{ Respiratory disease } & Yes & $57(21.5)$ & $30(22.6)$ & $27(20.5)$ & 0.677 \\
\hline & No & $208(78.5)$ & $103(77.4)$ & $105(79.5)$ & \\
\hline \multirow[t]{2}{*}{ Central nervous system disease } & Yes & $72(26.9)$ & $48(36.4)$ & $23(17.4)$ & 0.001 \\
\hline & No & $195(73)$ & $84(63.4)$ & $109(82.6)$ & \\
\hline \multirow[t]{2}{*}{ Oliguria } & Yes & $125(49.4)$ & $63(47.4)$ & $62(51.7)$ & 0.495 \\
\hline & No & $128(50.6)$ & $70(52.6)$ & $70(52.6)$ & \\
\hline \multirow[t]{2}{*}{ Anemia (hemoglobin $<12$ g/dL) } & Yes & $158(69.0)$ & $68(58.1)$ & $90(80.4)$ & $<0.001$ \\
\hline & No & $71(31.0)$ & $49(41.9)$ & $22(19.6)$ & \\
\hline \multirow[t]{2}{*}{ Acute kidney injury } & Yes & $145(52.3)$ & $80(56.3)$ & $65(48.1)$ & 0.173 \\
\hline & No & $132(47.7)$ & $62(43.7)$ & $70(51.9)$ & \\
\hline \multirow[t]{2}{*}{ Intensive care unit mortality } & Yes & $188(68)$ & $106(74.6)$ & $82(60.7)$ & 0.013 \\
\hline & No & $89(32.0)$ & $36(25.4)$ & $53(39.3)$ & \\
\hline \multirow[t]{2}{*}{ Ventilation support } & Yes & $176(67.9)$ & $95(73)$ & $79(62.2)$ & 0.062 \\
\hline & No & $195(32.1)$ & $35(26.9)$ & $48(37.8)$ & \\
\hline \multirow[t]{2}{*}{ Inotropes support } & Yes & $102(39.3)$ & $51(38)$ & $51(41.4)$ & 0.577 \\
\hline & No & $157(60.6)$ & $83(61.9)$ & $72(58)$ & \\
\hline
\end{tabular}

HIV, human immunodeficiency virus

2.8-fold and 5-fold odds for AKI development. ${ }^{22}$ However, there are limited studies that have examined the influence of HIV in hospitalized patients in the ICU setting. In developed countries, HIV infection has an insignificant role in AKI development in the ICU settings compared to LMIC. ${ }^{10}$

Unlike previous studies that showed old age $>50$ years as a positive predictor for $\mathrm{AKI}$, we found no association in our study. ${ }^{26}$ Our study population was relatively young with less than $30 \%$ above age 50 years, a reflection of the reduced life span in developing countries like Zambia.

In our study, the overall ICU mortality rate was $68 \%$ and was significantly high in the AKI group vs non-AKI group. The high overall mortality rate is consistent to previous studies. ${ }^{27,28}$ Almost 70 and $40 \%$ of our reviewed patients were on ventilation and inotropic supports, respectively. From an analysis that included 200 ventilated patients in the main ICU at a tertiary hospital in India, Sudarsanam et al. found $72 \%$ mortality rate. ${ }^{28}$ In this study, the type of respiratory failure and the receiving inotrope support predicted ICU mortality. ${ }^{28}$

Despite the high death rate in the AKI group, AKI was a negative dependent predictor for ICU mortality. Various studies have reported increased mortality rates in the ICU ${ }^{29,30}$ and worse among patients with AKI compared to those without AKI., ${ }^{1,12}$ Through a retrospective analysis of 152 admissions to the ICU, Peres et al. reported $36 \%$ overall mortality rate with $52 \%$ vs $5.8 \%$ in the AKI and non-AKI groups, respectively, of which mechanical ventilation predicted a 10 -fold mortality rate. ${ }^{12}$ Our study findings are similar to Peres et al. who reported AKI as a negative predictor for ICU mortality. ${ }^{12}$

In our study, the presence of DM and respiratory disease strongly predicted ICU mortality by almost threefold each. Sudarsanam et al. in an observational study of 200 mechanically ventilated patients at a tertiary hospital in India also found respiratory disease as a 2.7-fold predictor of ICU mortality. ${ }^{28}$ Previous studies have shown conflicting outcomes of DM patients admitted to the ICU or the influence of male gender in the ICU, a finding in our study. ${ }^{31,32}$ The increased levels of inflammatory cytokines associated with hyperglycemia ${ }^{32}$ may explain the poorer outcomes in DM patients. Esposito et al. reported increased levels of inflammatory cytokines, interleukin (IL) 6,18 , and TNFa, that were associated with acute levels of hyperglycemia. ${ }^{32}$ However, Siegelaar et al. in a meta-analysis that indexed 141 articles showed no overall ICU survival benefit in nondiabetics. ${ }^{33}$ However, 1.4 -fold mortality rate was observed in DM patients admitted to surgical ICU in this study. ${ }^{33}$ 
Table 2: Predictors of acute kidney injury in intensive care unit

\begin{tabular}{|c|c|c|c|c|c|c|}
\hline \multirow[b]{2}{*}{ Characteristic } & \multicolumn{3}{|c|}{ Crude OR } & \multicolumn{3}{|c|}{ Adjusted OR } \\
\hline & $O R$ & $95 \% \mathrm{Cl}$ & $p$ value & $O R$ & $95 \% \mathrm{Cl}$ & $p$ value \\
\hline \multicolumn{7}{|l|}{ Age (years) } \\
\hline$<50$ & 0.93 & $0.72-1.21$ & 0.605 & & & \\
\hline$>50+$ & 1 & & & & & \\
\hline \multicolumn{7}{|l|}{ Gender } \\
\hline Male & 1.18 & $0.93-1.49$ & 0.173 & & & \\
\hline Female & 1 & & & & & \\
\hline \multicolumn{7}{|c|}{ Diabetes mellitus } \\
\hline Yes & 1.11 & $0.78-1.59$ & 0.553 & & & \\
\hline No & 1 & & & & & \\
\hline \multicolumn{7}{|l|}{ Hypertension } \\
\hline Yes & 1.27 & $0.96-1.68$ & 0.096 & & & \\
\hline No & 1 & & & & & \\
\hline \multicolumn{7}{|l|}{ HIV positive } \\
\hline Yes & 1.78 & $1.23-2.59$ & 0.003 & 2.38 & $1.33-4.26$ & 0.004 \\
\hline No & 1 & & & 1 & & \\
\hline \multicolumn{7}{|l|}{ Sepsis } \\
\hline Yes & 1.90 & $1.48-2.44$ & $<0.001$ & & & \\
\hline No & 1 & & & & & \\
\hline \multicolumn{7}{|c|}{ Cardiac disease } \\
\hline Yes & 1.34 & $0.96-1.87$ & 0.084 & & & \\
\hline No & 1 & & & & & \\
\hline \multicolumn{7}{|c|}{ Respiratory disease } \\
\hline Yes & 0.75 & $0.51-1.11$ & 0.153 & & & \\
\hline No & 1 & & & & & \\
\hline \multicolumn{7}{|l|}{ Oliguria } \\
\hline Yes & 3.25 & $2.42-4.35$ & $<0.001$ & 4.23 & $2.43-7.34$ & 0.016 \\
\hline No & 1 & & & 1 & & \\
\hline \multicolumn{7}{|l|}{ NSAIDs } \\
\hline Yes & 0.90 & $0.71-1.15$ & 0.903 & & & \\
\hline No & 1 & & & & & \\
\hline \multicolumn{7}{|l|}{ Anemia } \\
\hline Yes & 1.04 & $0.78-1.37$ & 0.811 & & & \\
\hline No & 1 & & & & & \\
\hline \multicolumn{7}{|c|}{ Inotropes support } \\
\hline Yes & 1.41 & $1.09-1.82$ & 0.008 & & & \\
\hline No & 1 & & & & & \\
\hline \multicolumn{7}{|c|}{ Ventilator support } \\
\hline Yes & 1.22 & $0.94-1.59$ & 0.136 & & & \\
\hline No & 1 & & & & & \\
\hline
\end{tabular}

High levels of inflammatory cytokines have been found in hospitalized septic males vs females. Nasir et al. in Karachi found $60.7 \pm 13.4 \mathrm{pg} / \mathrm{mL}$ vs $28.1 \pm 7.2 \mathrm{pm} / \mathrm{mL}$ IL6 in males vs females, respectively. ${ }^{34}$ The major limitation to the study was that many records were unavailable due to the nonelectronic health recordkeeping. Additionally, the study was retrospective with a small sample size for major conclusions.

\section{Conclusion}

The outcome of AKI among patients admitted to the ICU was highly impacted by HIV and DM comorbidities. Extra care and attentiveness should be employed toward such patients in a setting of limited resources. To our knowledge, this is the first study examining the impact of HIV and DM in the ICU setting in Zambia. 
Table 3: Predictors for ICU mortality

\begin{tabular}{|c|c|c|c|c|c|c|}
\hline \multirow[b]{2}{*}{ Characteristic } & \multicolumn{3}{|c|}{ Crude OR } & \multicolumn{3}{|c|}{ Adjusted OR } \\
\hline & $O R$ & $95 \% \mathrm{Cl}$ & pvalue & $O R$ & $95 \% \mathrm{Cl}$ & $p$ value \\
\hline \multicolumn{7}{|l|}{ Age (years) } \\
\hline$<50$ & 0.69 & $0.51-0.93$ & 0.016 & & & \\
\hline$>50+$ & 1 & & & & & \\
\hline \multicolumn{7}{|l|}{ Gender } \\
\hline Male & 1.38 & $1.07-1.78$ & 0.014 & 1.73 & $1.21-2.47$ & 0.003 \\
\hline Female & 1 & & & 1 & & \\
\hline \multicolumn{7}{|c|}{ Diabetes mellitus } \\
\hline Yes & 2.51 & $1.37-4.61$ & 0.003 & 2.82 & $1.28-6.24$ & 0.010 \\
\hline No & 1 & & & 1 & & \\
\hline \multicolumn{7}{|l|}{ Hypertension } \\
\hline Yes & 1.43 & $1.04-1.97$ & 0.029 & & & \\
\hline No & 1 & & & & & \\
\hline \multicolumn{7}{|l|}{ HIV positive } \\
\hline Yes & 1.08 & $0.76-1.52$ & 0.675 & & & \\
\hline No & 1 & & & & & \\
\hline \multicolumn{7}{|l|}{ Sepsis } \\
\hline Yes & 1.25 & $0.96-1.61$ & 0.092 & & & \\
\hline No & 1 & & & & & \\
\hline \multicolumn{7}{|c|}{ Cardiac disease } \\
\hline Yes & 1.46 & $0.99-2.16$ & 0.056 & & & \\
\hline No & 1 & & & & & \\
\hline \multicolumn{7}{|c|}{ Respiratory disease } \\
\hline Yes & 1.94 & $1.30-2.89$ & 0.001 & 2.57 & $1.43-4.59$ & 0.001 \\
\hline No & 1 & & & 1 & & \\
\hline \multicolumn{7}{|l|}{ Oliguria } \\
\hline Yes & 1.25 & $0.96-1.63$ & 0.093 & & & \\
\hline No & 1 & & & & & \\
\hline \multicolumn{7}{|l|}{ NSAIDs } \\
\hline Yes & 1.03 & $0.79-1.32$ & 0.848 & & & \\
\hline No & 1 & & & & & \\
\hline \multicolumn{7}{|l|}{ Anemia } \\
\hline Yes & 0.88 & $0.65-1.19$ & 0.882 & & & \\
\hline No & 1 & & & & & \\
\hline \multicolumn{7}{|c|}{ Inotropes support } \\
\hline Yes & 1.92 & $1.41-2.60$ & $<0.001$ & 1.77 & $1.20-2.62$ & 0.004 \\
\hline No & 1 & & & 1 & & \\
\hline \multicolumn{7}{|c|}{ Ventilator support } \\
\hline Yes & 1.73 & $1.31-2.28$ & $<0.001$ & 1.57 & $1.08-2.27$ & 0.017 \\
\hline No & 1 & & & & 1 & \\
\hline
\end{tabular}

NSAIDs, nonsteroidal anti-inflammatory drugs; HIV, human immunodeficiency virus; ICU, intensive care unit; OR, odds ratio; $\mathrm{Cl}$, confidence interval

\section{References}

1. Abd ElHafeez S, Tripepi G, Quinn R, Naga Y, Abdelmonem S, AbdelHady $M$, et al. Risk, predictors, and outcomes of acute kidney injury in patients admitted to intensive care units in Egypt. Sci Rep 2017;7(1):1-8. DOI: 10.1038/s41598-017-17264-7.

2. Santos PR, Monteiro DLS. Acute kidney injury in an intensive care unit of a general hospital with emergency room specializing in trauma: an observational prospective study. BMC Nephrology 2015;16:1-6. DOI: $10.1186 / \mathrm{s} 12882-015-0026-4$.
3. Halle MPE, Chipekam NM, Beyiha G, Fouda H, Coulibaly A, Hentchoya $\mathrm{R}$, et al. Incidence, characteristics and prognosis of acute kidney injury in Cameroon: a prospective study at the Douala general hospital. Renal Failure 2018;40(1):30-37. DOI: 10.1080/0886022X.2017. 1419970.

4. Park WY, Hwang EA, Jang MH, Park SB, Kim HC. The risk factors and outcome of acute kidney injury in the intensive care units. Korean J Intern Med 2010;25(2):181-187. DOI: 10.3904/kjim.2010.25.2.181.

5. Tejera D, Varela F, Acosta D, Figueroa S, Benencio S, Verdaguer C, et al. Epidemiology of acute kidney injury and chronic kidney disease in 
the intensive care unit. Rev Bras Ter Intensiva 2017;29(4):444-452. DOI: $10.5935 / 0103-507 X .20170061$.

6. Makris K, Spanou L. Acute kidney injury: definition, pathophysiology and clinical phenotypes. Clin Biochem Rev 2016;37(2):85-98.

7. Olowu WA, Niang A, Osafo C, Ashuntantang G, Arogundade FA, Porter J, et al. Outcomes of acute kidney injury in children and adults in sub-Saharan Africa: a systematic review. Lancet Glob Health 2016;4(4):e242-e250. DOI: 10.1016/S2214-109X(15)00322-8.

8. Singer M, Deutschman CS, Seymour CW, Shankar-Hari M, Annane D, Bauer $\mathrm{M}$, et al. The third international consensus definitions for sepsis and septic shock (sepsis-3). JAMA 2016;315(8):801-810. DOI: 10.1001/ jama.2016.0287.

9. Gül F, Arslantaş MK, Cinel I, Kumar A. Changing definitions of sepsis. Turkish J Anaesthesiol Reanim 2017;45(3):129-138. DOI: 10.5152/ TJAR.2017.93753.

10. Malhotra R, Kashani KB, Macedo E, Kim J, Bouchard J, Wynn S, et al. A risk prediction score for acute kidney injury in the intensive care unit. Nephrol Dial Transplant 2017;32(5):814-822. DOI: 10.1093/ndt/ gfx026.

11. Abd ElHafeez S, Bolignano D, D’Arrigo G, Dounousi E, Tripepi G, Zoccali $C$. Prevalence and burden of chronic kidney disease among the general population and high-risk groups in Africa: a systematic review. BMJ Open 2018;8(1):1-32. DOI: 10.1136/bmjopen-2016015069.

12. Peres $L A$, Wandeur $V$, Matsuo T. Predictors of acute kidney injury and mortality in an intensive care unit. J Bras Nefrol 2015;37:38-46. DOI: 10.5935/0101-2800.20150007.

13. Vikrant S, Gupta D, Singh M. Epidemiology and outcome of acute kidney injury from a tertiary care hospital in India. Saudi J Kidney Dis Transpl 2018;29(4):956-966. DOI: 10.4103/1319-2442. 239633.

14. Boswell MT, Rossouw TM. Approach to acute kidney injury in HIVinfected patients in south Africa. South Afr J HIV Med 2017;18(1):1-7. DOI: 10.4102/sajhivmed.v18i1.714.

15. Vachiat Al, Musenge E, Wadee S, Naicker S. Renal failure in HIVpositive patients—a South African experience. Clin Kidney J 2013;6(6): 584-589. DOI: $10.1093 / \mathrm{ckj} / \mathrm{sft} 128$.

16. Wyatt CM. Kidney disease and HIV infection. Topics in antiviral medicine 2017;25(1):13-16.

17. Fabian J, Naicker S. HIV and kidney disease in sub-Saharan Africa. Nat Rev Nephrol 2009;5(10):591-598. DOI: 10.1038/nrneph.2009.141.

18. Kalim S, Szczech LA, Wyatt CM. Acute kidney injury in HIV-infected patients. Semin Nephrol 2008;28(6):556-562. DOI: 10.1016/ j.semnephrol.2008.08.008.

19. Li Y, Shlipak MG, Grunfeld C, Choi Al. Incidence and risk factors for acute kidney injury in HIV infection. Am J Nephrol 2012;35(4):327-334. DOI: 10.1159/000337151.

20. Lopes JA, Melo MJ, Viegas A, Raimundo M, Camara I, Antunes F, et al. Acute kidney injury in hospitalised-HIV infected patients: a cohort analysis. Nephrol Dial Transplant 2011;26(12):3888-3894. DOI: 10.1093/ndt/gfr192.

21. Li X, Zhuang S. Acute kidney injury in HIV infection. J Trop Dis 2013;1(1):1-11.

22. Wyatt $\mathrm{CM}$, Arons RR, Klotman PE, Klotman ME. Acute renal failure in hospitalized patients with HIV: risk factors and impact on in-hospital mortality. AIDS 2006;20(4):561-565. DOI: 10.1097/01. aids.0000210610.52836.07.

23. Seedat F, Martinson N, Motlhaoleng K, Abraham P, Mancama D, Naicker $S$, et al. Acute kidney injury, risk factors, and prognosis in hospitalized HIV-infected adults in south Africa, compared by Tenofovir exposure. AIDS Res Hum Retroviruses 2017;33(1):33-40. DOI: 10.1089/aid.2016.0098.

24. Izzedine $\mathrm{H}$, Baumelou A, Deray G. Acute renal failure in HIV patients. Nephrol Dial Transplant 2007;22(10):2757-2762. DOI: 10.1093/ndt/ gfm404.

25. Kalyesubula R, Perazella MA. Nephrotoxicity of HAART. AIDS Res Treat 2011; 1-11. DOI: 10.1155/2011/562790.

26. Ponce D, Zorzenon Cde P, Santos NY, Teixeira UA, Balbi AL. Acute kidney injury in intensive care unit patients: a prospective study on incidence, risk factors and mortality. Rev BrasTer Intensiva 2011;23(3):321-326. DOI: 10.1590/S0103-507X2011000300010.

27. Siddiqui S. Mortality profile across our intensive care units: a 5-year database report from a Singapore restructured hospital. Indian J Crit Care Med 2015;19(12):726-727. DOI: 10.4103/0972-5229. 171401.

28. Sudarsanam TD, Jeyaseelan L, Thomas K, John G. Predictors of mortality in mechanically ventilated patients. Postgrad Med J 2005;81(962):780-783. DOI: 10.1136/pgmj.2005.033076.

29. Smith ZA, Ayele Y, McDonald P. Outcomes in critical care delivery at Jimma University Specialised Hospital, Ethiopia. Anaesth Intensive Care, 2013;41(3):363-368. DOI: 10.1177/0310057X1304100314.

30. Okafor UV. Challenges in critical care services in Sub-Saharan Africa: perspectives from Nigeria. Indian J Crit Care Med 2009;13(1):25-27. DOI: 10.4103/0972-5229.53112

31. Sakr Y, Elia C, Mascia L, Barberis B, Cardellino S, Livigni S, et al. The influence of gender on the epidemiology of and outcome from severe sepsis. Critical Care 2013;17(2):R50. DOI: 10.1186/cc12570.

32. Esposito K, Nappo F, Marfella R, Giugliano G, Giugliano F, Ciotola M, et al. Inflammatory cytokine concentrations are acutely increased by hyperglycemia in humans. Circulation 2002;106(16):2067-2072. DOI: 10.1161/01.cir.0000034509.14906.ae.

33. Siegelaar SE, Hickmann M, Hoekstra JBL, Holleman F, DeVries JH. The effect of diabetes on mortality in critically ill patients: a systematic review and meta-analysis. Crit Care 2011;15(5):R205-R205. DOI: 10.1186/cc10440.

34. Nasir N, Jamil B, Siddiqui S, Talat N, Khan FA, Hussain R. Mortality in sepsis and its relationship with Gender. Pak J Med Sci 2015;31(5): 1201-1206. DOI: 10.12669/pjms.315.6925. 